\title{
Terminal Ileum Resection
}

National Cancer Institute

\section{Source}

National Cancer Institute. Terminal lleum Resection. NCI Thesaurus. Code C51610.

Surgical removal of part or all of the terminal portion of the ileum. 